Research Article

\title{
Purification of Anthocyanins Derived from Black Kidney Bean (Phaseolus vulgaris L.) by a Simulated Moving Bed
}

\author{
Liangyu Li, ${ }^{1,2}$ Cheng Luo, ${ }^{3}$ and Xiqun Zheng $\mathbb{D}^{1,4}$ \\ ${ }^{1}$ National Coarse Cereal Engineering Technology Research Center, Heilongjiang Bayi Agricultural University, \\ Daqing 163319, China \\ ${ }^{2}$ College of Forestry, Northeast Forestry University, Harbin 150040, China \\ ${ }^{3}$ College of Food Science, Heilongjiang Bayi Agricultural University, Daqing 163319, China \\ ${ }^{4}$ Engineering Research Center of Processing and Utilization of Grain By-Products, Ministry of Education, Daqing 163319, China
}

Correspondence should be addressed to Xiqun Zheng; zhengxiqun@126.com

Received 26 January 2021; Revised 26 March 2021; Accepted 31 May 2021; Published 16 June 2021

Academic Editor: Wagdy Eldehna

Copyright (c) 2021 Liangyu Li et al. This is an open access article distributed under the Creative Commons Attribution License, which permits unrestricted use, distribution, and reproduction in any medium, provided the original work is properly cited.

Purification of anthocyanins derived from black kidney bean (Phaseolus vulgaris L.) by column chromatography and simulated moving bed $(\mathrm{SMB})$ methods was investigated, and the anthocyanins of black kidney bean were identified. The SMB had advantages over column chromatography in processing efficiency, operation cost, and automation degree in contrast testing. The best SMB conditions resulted in purity and yield of black kidney bean anthocyanins of $24.61 \pm 0.21 \%$ and $87.85 \pm 0.32 \%$, respectively. The half maximal inhibitory concentration $\left(\mathrm{IC}_{50}\right)$ of 1,1-diphenyl-2-picrylhydrazyl (DPPH) scavenging activity and 2,2'-azinobis-(3-ethylbenzthiazoline-6-sulphonate) radical (ABTS+•) scavenging activity was 0.95 and 2.14 of refined anthocyanins, respectively, indicating strong antioxidant capacity. Three anthocyanins were detected and identified by UPLC-TripleTOF/MS from black kidney bean skins: delphinidin-3-O-glucoside, petunidin-3-O-glucoside, and malvidin-3-O-glucoside. The experimental results suggested that SMB may help promote industrialization and purification of anthocyanins from colored kidney beans as well as from other plant materials.

\section{Introduction}

Kidney bean (Phaseolus vulgaris L.) is a widely cultivated legume crop in China and has important nutritional and medicinal value. In recent years, the proteins $[1,2]$, oils [3], lectins [4], peptides [5], starch [6-8], polyphenols $[9,10]$, and flavonoids [11] of kidney bean have been researched, representing a great achievement. The utilization of kidney beans will increase with the development of these studies and result in discarding a lot of skin. The skin of colored kidney beans possesses superior antioxidative activity compared with white kidney beans because it contains anthocyanins [12, 13]. Most studies have focused on the antioxidant characteristics $[14,15]$ and the effect of processing methods on the bioactivity of anthocyanins of kidney beans [16], but research is rare on the purification method of anthocyanins derived from colored kidney beans. Studies on colored kidney beans have focused on red and Swedish brown kidney beans, with few on black kidney beans.

The methods for purifying anthocyanins include adsorption on macroporous resins [17-19], liquid and subcritical carbon dioxide [20], membrane separation [21], preparative high-performance liquid chromatography [22], aqueous two-phase extraction $[23,24]$, ionic liquid solutions [25], high-speed countercurrent chromatography [26], high voltage paper electrophoresis [27], and column chromatography [28]. These methods can achieve high purity, but many are laboratory-level and cannot be industrialized. Some integration and combination technologies have been used to purify anthocyanins, and the process efficiency has been improved, but there is still some gap before industrialization [29-31]. The continuous chromatography system is a type of simulated moving bed (SMB) chromatography and is an efficient and advanced purification technology. 
Compared with traditional column chromatography, the SMB method has a short processing time and good productivity and requires less buffer and volume of resin [32]. The SMB system has been used in many fields of protein separation [33], Ginkgo biloba enrichment [34], and heparin purification [35]. The use of the SMB system in purifying anthocyanins has not been reported. The objective of this study was to purify the anthocyanins derived from black kidney bean using the SMB system and investigate the in vitro antioxidant properties of black kidney bean anthocyanins (BKBA). The principal components of BKBA were also discussed. This will provide useful information for developing a new industrialization purification method for anthocyanins (see Figure 1).

\section{Experimental}

\subsection{Methods}

2.1.1. Black Kidney Bean Collection. Black kidney bean grown in Baiquan, Heilongjiang Province, was collected during autumn 2017 . The beans were stored at $-20^{\circ} \mathrm{C}$ within $2 \mathrm{~h}$ of collection.

2.1.2. BKBA Extraction. Before extraction, black kidney beans (cv. LongYun no. 4) were soaked at $30^{\circ} \mathrm{C}$ for $8 \mathrm{~h}$, and the skin was obtained. The BKBA was extracted by the method of Li et al. [36]: the bran was extracted by an ultrasonic processor (JinBaiTe, China) twice with $70 \%(\mathrm{v} / \mathrm{v})$ ethanol and $0.6 \%$ hydrochloric acid was added for $20 \mathrm{~min}$. Operation parameters were set as follows: the liquid material ratio $20 \mathrm{~mL} / \mathrm{g}$, ultrasonic frequency $24 \mathrm{kHz}$, ultrasonic power $300 \mathrm{~W}$, extraction temperature $30^{\circ} \mathrm{C}$, and it was evaporated to dryness using a rotary evaporator (Buchi, Switzerland) at $50^{\circ} \mathrm{C}$. The content of BKBA anthocyanin is about $40 \mathrm{mg} / \mathrm{g}$ [37]; the amount $(21.5 \mathrm{mg} / \mathrm{g})$ obtained by this method was consistent with previous studies [38].

2.1.3. Effects of Separation Conditions on the Purification of $B K B A$ by $A B-8$ Resin. The pretreated $A B-8$ resin (the macroporous slightly polar adsorbent resin of polystyrene, pore size $13-14 \mathrm{~nm}$, specific surface area $450-530 \mathrm{~m}^{2} / \mathrm{g}$, water content $65-75 \%$, bulk density $0.62-0.72 \mathrm{~g} / \mathrm{mL}$, particle size $0.315-1.25 \mathrm{~mm}$, porosity $42-46 \%$, white opaque spherical particles) was put into a chromatography column $(15 \times 500 \mathrm{~mm})$ (constructed by the National Coarse Cereal Engineering Technology Research Center). The AB-8 absorbs BKBA through surface adsorption and hydrogen bonds, forming a relatively stable structure and completing the adsorption process. Then, the BKBA is desorbed from the resin by washing with different polar solvents and constantly destroying the formed hydrogen bonds. Anthocyanins are compounds with a 2-phenyl chromogenic ketone structure; in addition to a keto carbonyl group, they often contain alcohol hydroxyl and phenol hydroxyl groups. Different anthocyanins have different polarities. Therefore, the molecular structure of anthocyanins contains both hydrogen-bonded donor and hydrogen-bonded receptor groups, so polar and nonpolar resins can be used for adsorption and desorption. The operation parameters were set as follows: column temperature of $30^{\circ} \mathrm{C}$; BKBA concentrations of 100, 150, 200, 250, and $300 \mathrm{mg} / \mathrm{mL}$ (desorption flow rate: $2.0 \mathrm{~mL} / \mathrm{min}$ ); desorption flow rates of 1.0, 1.5, 2.0, 2.5, and $3.0 \mathrm{~mL} / \mathrm{min}$ (BKBA concentration: $200 \mathrm{mg} / \mathrm{mL}$ ). After saturated feed, the chromatography column was washed by deionized water (3 BV) and desorbed by $60 \%$ ethanol (3 BV). The lyophilized product was collected, and the purity and yield were calculated to study the effect of concentration on the purification of $\mathrm{BKBA}$ by the $\mathrm{AB}-8$ resin.

\subsubsection{Purification of BKBA by Column Chromatography.} The column chromatography was a fixed mode and a true moving bed (TMB). The AB- 8 resin was put into preparative chromatography column $(15 \times 500 \mathrm{~mm})$. The operation parameters were set as follows: column temperature of $30^{\circ} \mathrm{C}$, concentration of $200 \mathrm{mg} / \mathrm{mL}$, and desorption flow rate of $2.0 \mathrm{~mL} / \mathrm{min}$. After saturating the feed, the chromatography column was washed by deionized water (3 BV) and desorbed by $20 \%, 40 \%$, and $60 \%$ ethanol (3 BV), respectively. The eluent was, respectively, collected, and finally, the samples were analyzed by an ultraviolet spectrophotometer, and the antioxidant activities were determined, to study the purification of BKBA by column chromatography.

2.1.5. Purification of BKBA by SMB. The SMB (20 columns of $25 \mathrm{~mm} \times 500 \mathrm{~mm}$, National Coarse Cereal Engineering Technology Research Center) was used in this experiment. Using the SMB technology, the traditional SMB was improved according to the technical requirements. The whole process cycle consisted of a disk with a plurality of resin columns (20 columns) and a porous distribution valve. Through the rotation of the disk and the conversion of the valve mouth, the separation column completed the whole process of adsorption, purification, desorption, and regeneration in a process cycle. In the continuous separation system, the process steps were carried out simultaneously. Twenty chromatography columns $(25 \mathrm{~mm} \times 500 \mathrm{~mm})$ were used in this study for the separation process.

Studies suggest that anthocyanins mainly exist in the $40 \%$ ethanol solution of black kidney bean. Accordingly, the chromatographic separation system of SMB separation for BKBA was divided into five parts: adsorption zone, refined zone, desorbing zone, regenerative zone, and water washing zone. The raw material was added to the system at the adsorption zone, where the anthocyanins were absorbed by the resin. The regenerative zone can also be regarded as the impurity removal region. The $20 \%$ ethanol was applied to remove proteins, polysaccharides, and other impurities. The desorption zone was eluted with $40 \%$ ethanol to obtain high purity BKBA products. In the regenerated zone, $80 \%$ ethanol was used to rinse the chromatographic column, and other impurities in the column were completely removed. In the wash zone, deionized water was used to remove ethanol from the chromatographic column and prepare for the feeding zone. The system had 20 chromatographic columns. When the system was running, the resin column and 


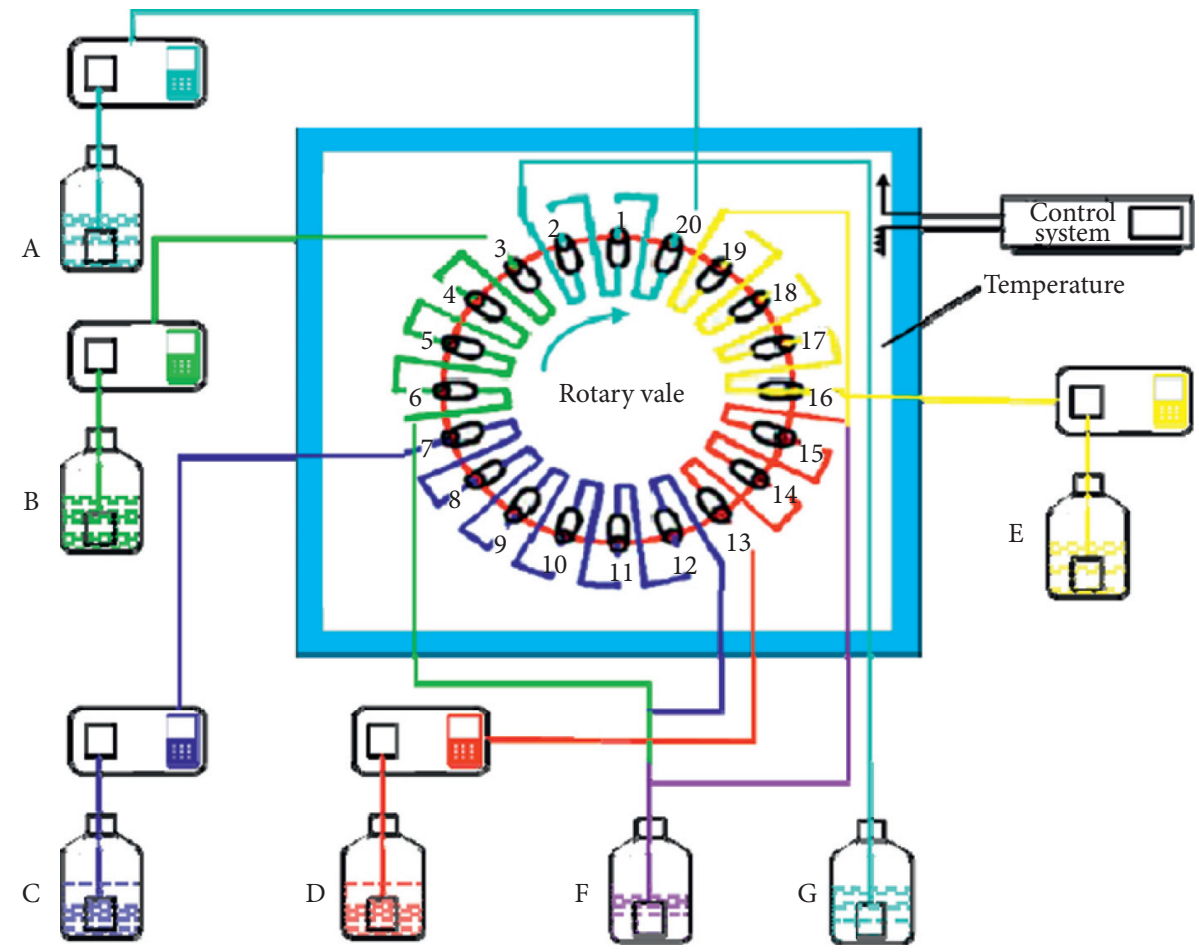

FIGURE 1: The assembly diagram of the SMB system for purification of BKBA. Note: A: desorbing solution (40\% ethanol), B: refined solution (20\% ethanol), C: adsorption solution (raw anthocyanin solution), D: water washing solution (deionized water), E: regenerative solution (80\% ethanol), F: waste water, and G: refined anthocyanins.

supporting chassis were in the fixed positions. The rotary valve rotated at a regular rate, and consequently, 20 chromatographic columns were used during the operation of five procedures, including continuous adsorption, purification, elution, regeneration, and water washing. Twenty slots were matched with the stiff end of the 20 columns. When the system was running, the liquid flow into or out of the fixed slot was constant and uninterrupted. When the rotating valves rotated in a circle, each column of resin underwent a complete process of adsorption, refining, desorption, regeneration, and water washing. On the basis of single column experiment, the equivalence and conversion relation between the SMB and TMB is linked by the following equations [39].

The conversion relationship between solid state flow and switching time of SMB is as follows:

$$
Q_{S}=\frac{1-\varepsilon}{\tau} \text {. }
$$

Flow ratio formula of TMB is as follows:

$$
m_{j}=\frac{Q_{j}^{\mathrm{TMB}}}{Q_{S}} .
$$

The conversion relationship between the flow ratio of SMB and the flow ratio of TMB is as follows:

$$
\frac{Q_{j}^{\mathrm{SMB}}}{Q_{S}}=\frac{Q_{j}^{\mathrm{TMB}}}{Q_{S}}+\frac{\varepsilon}{1-\varepsilon} .
$$

The conversion relationship between the flow rate ratio and the flow ratio of TMB is as follows:

$$
\frac{u_{j}^{\mathrm{TMB}}}{u_{s}}=\frac{(1-\varepsilon) D_{j}^{\mathrm{TMB}}-\varepsilon Q_{s}}{\varepsilon Q_{s}}=\frac{1-\varepsilon}{\varepsilon} \frac{Q_{j}^{\mathrm{SMB}}}{Q_{s}}-1,
$$

where $Q_{S}$ is the solid state flow, $Q_{j}$ is the mobile state flow of zone $j, \varepsilon$ is the porosity, $t$ is the retention time, $m_{\mathrm{j}}$ is the flow ratio of zone $j$ at TMB, $u_{j}$ is the flow rate ratio of zone $j, u_{s}$ is the flow rate ratio of solid state, and $D_{j}$ is the axial diffusion coefficient.

According to the adsorption experiments of $\mathrm{AB}-8$ resin for $\mathrm{BKBA}$, the parameters, including saturated adsorption capacity, saturation time, eluent, elution and regeneration agent and water flow rate, regeneration and washing effect, and the actual operation performance of resin and equipment, were determined. The types of distribution of IE-SMB chromatographic separation zones were defined. The initial process parameters were calculated according to the static and dynamic experiments of resin and the material balance equation of the TMB model. According to the basic parameters of the TMB experiment, the technological parameters of the separation and purification of BKBA by SMB were further optimized.

2.1.6. Determination of Anthocyanins. Two samples of anthocyanin solution were diluted with potassium chloride buffer ( $\mathrm{pH} 1.0)$ and sodium acetate buffer $(\mathrm{pH} 4.5)$, the ratio of the two solutions was $1: 15$, using distilled water as a blank, and adsorption was measured by an ultraviolet spectrophotometer (Evolution 220, Thermo Fisher Scientific, USA) at $515 \mathrm{~nm}$ and $700 \mathrm{~nm}$. The anthocyanin content was calculated by formula (5), with cyanidin-3-O-glucoside $(\mathrm{C} 3 \mathrm{G})$ as the standard: 
content of anthocyanins $(\mathrm{mg} / \mathrm{mL})=\Delta A \times \mathrm{Mw} \times \mathrm{DF} \times \frac{10^{3}}{\varepsilon} \times l$,

where $\triangle A$ is the difference of absorbance, $\Delta A=\left(A_{510 \mathrm{~nm}}-A_{700 \mathrm{~nm}}\right)_{\mathrm{pH} 1.0}-\left(A_{510 \mathrm{~nm}}-A_{700 \mathrm{~nm}}\right)_{\mathrm{pH} 4.5}, \mathrm{Mw}$ is the molecular weight of C3G $(449.2 \mathrm{~g} / \mathrm{mol})$, DF is the dilution multiple, $\varepsilon=26,900$ is the molar extinction coefficient of $\mathrm{C} 3 \mathrm{G}$, and 1 is the optical distance of the cuvette $(\mathrm{cm})$.

2.1.7. UPLC-Triple-TOF/MS Analysis for BKBA. The UPLCTriple-TOF/MS was determined by the method reported by Wang et al. [40]. The UPLC-Triple-TOF/MS system was TOF $5600^{+}$of Acquity $^{\mathrm{TM}}$ ultra Triple (Waters Corporation, Milford, MA, USA) equipped with a ZORBAX-SB $\mathrm{C}_{18}$ $(4.6 \mathrm{~mm} \times 100 \mathrm{~mm}, 1.8 \mu \mathrm{m}$, Agilent Co. Ltd., Palo Alto, CA, USA). The wavelength of the UV detector was set at $520 \mathrm{~nm}$. The injection volume was $5 \mu \mathrm{L}$ and the column temperature was $30^{\circ} \mathrm{C}$. Mobile phase A consisted of a water solution containing $0.1 \%(\mathrm{v} / \mathrm{v})$ formic acid, while mobile phase B was an acetonitrile solution containing $0.1 \%(\mathrm{v} / \mathrm{v})$ formic acid. The gradient program at a flow rate of $0.8 \mathrm{~mL} / \mathrm{min}$ was as follows: $0-25 \mathrm{~min}$ : $5 \% \mathrm{~B}$; $25-35 \mathrm{~min}$ : $25 \% \mathrm{~B}$; $35-38 \mathrm{~min}$ : $95 \%$ $B$. It was equipped with an electrospray ionization source (AB Sciex Co. Ltd., USA) and positive ion mode monitoring, the atomizing gas $\mathrm{GS}_{1}$ was $50 \mathrm{psi}$, atomizing gas $\mathrm{GS}_{2}$ was $50 \mathrm{psi}$, and the air curtain gas (CUR) was $35 \mathrm{psi}$, the ion source temperature (TEM) was $600^{\circ} \mathrm{C}$ (positive), the ion source voltage (IS) was $5,500 \mathrm{~V}$ (positive), and the $\mathrm{m} / z$ setting range was $100-1,500$. First level scan: cluster voltage (DP), $100 \mathrm{~V}$, and focus voltage (CE), $10 \mathrm{~V}$. Secondary scanning: mass spectrometry data were collected by TOF MS-Product Ion-IDA mode. CID energy was 20, 40, and $60 \mathrm{~V}$. Before injection, the mass axis was corrected by CDS pump, so that the mass axis error was less than $2 \mathrm{ppm}$. Compounds were identified using the SciFinder and Reaxys databases [41].

2.1.8. Determination of DPPH Radical Scavenging Activity. The DPPH (Sigma, USA) free radical scavenging activity was determined by the method of Maeda et al. with slight modification [42]. To the samples $(2 \mathrm{~mL})$ at different concentrations $(0-50 \mu \mathrm{g} / \mathrm{mL})$ was added $2 \mathrm{~mL}$ of $0.4 \mathrm{mM} \mathrm{DPPH}$ radicals. The mixture was shaken vigorously and left to stand for $30 \mathrm{~min}$ in darkness before the absorbance was measured at $517 \mathrm{~nm}$ against a methanol blank. Ascorbic acid (Vc) was used as a positive control. The percent inhibition of DPPH was calculated according to the following equation:

$$
\text { DPPH scavenging activity }(\%)=\left[\frac{A-B}{A}\right] \times 100,
$$

where $A$ is the absorbance of DPPH radical + methanol and $B$ is the absorbance of DPPH + test samples. All determinations were performed in triplicate. $\mathrm{IC}_{50}$ is the concentration of the sample needed to decrease $50 \%$ of the DPPH concentration relative to that of control.
2.1.9. Determination of ABTS $+\bullet$ Radical Scavenging Activity. The ABTS $+\bullet$ free radical scavenging activity was determined by the method of Arnao et al. and Zhang et al. with slight modification $[43,44]$. The ABTS (Sigma-Aldrich) solution $(7 \mathrm{mmol} / \mathrm{L} ; 5 \mathrm{~mL})$ and potassium persulfate solution $(2.45 \mathrm{mmol} / \mathrm{L} ; 5 \mathrm{~mL})$ were mixed in darkness for $12 \mathrm{~h}$, to produce $\mathrm{ABTS}+\bullet$. The ABTS $+\bullet$ solution was diluted with water, and the absorbance was $0.70 \pm 0.02$ at $734 \mathrm{~nm}$. The percentage inhibition of ABTS was calculated according to the following equation:

$$
\operatorname{ABTS} \text { scavenging activity }(\%)=\left[1-\frac{A_{1}-A_{2}}{A_{0}}\right] \times 100 \text {. }
$$

2.2. Statistical Analysis. The data are presented as means \pm SD. Statistical analyses were done using the statistical SAS program, and the significance of each group was verified by one-way ANOVA followed by Duncan's test at $P<0.05$.

\section{Results}

3.1. The Result of Separation Conditions on the Purification of $B K B A$ by $A B-8$ Resin. The results showed a significant effect of concentration on the purification of BKBA by AB- 8 resin (Figure 2). There were few differences in BKBA purity and yield at low concentrations $(100-200 \mathrm{mg} / \mathrm{mL})$, and BKBA purity and yield suddenly declined when the concentrations were above $200 \mathrm{mg} / \mathrm{mL}$. The high concentration led to inadequate contact between BKBA molecules and resin and a decline in adsorption capacity, which affected the BKBA purification by the AB- 8 resin. The best concentration was $200 \mathrm{mg} / \mathrm{mL}$.

The desorption flow rate of $\mathrm{AB}-8$ resin significantly affected BKBA purification (Figure 3 ). There were few differences in BKBA purity and yield at a low desorption flow rate $(1.0-2.0 \mathrm{~mL} / \mathrm{min})$ and the $\mathrm{BKBA}$ purity and yield suddenly decreased for a desorption flow rate above $2.0 \mathrm{~mL} /$ min. A higher adsorption flow rate of $\mathrm{AB}-8$ resin led to insufficient adsorption and lowered the adsorption capacity. That may have affected the BKBA purification. The best desorption flow rate was $2.0 \mathrm{~mL} / \mathrm{min}$.

3.2. Purification of BKBA by Column Chromatography. Scavenging capacity of BKBA and concentration of BKBA significantly differed with different EtOH concentrations (Figure 4). Most of the BKBA was concentrated in the $40 \%$ ethanol elution solution, and little was concentrated in deionized water or $20 \%$ ethanol or $60 \%$ ethanol elution solutions. In addition, the $40 \%$ ethanol had higher purity than the other eluents.

The results showed that the test samples and the positive control Vc had an inhibitory effect (Table 1), and the $\mathrm{IC}_{50}$ of $\mathrm{DPPH}$ and the $\mathrm{IC}_{50}$ of ABTS+ $\bullet$ scavenging activity of $40 \%$ ethanol solution were 0.95 and $2.14 \mu \mathrm{g} / \mathrm{mL}$, respectively. This was lower than in other samples, and scavenging activity was 


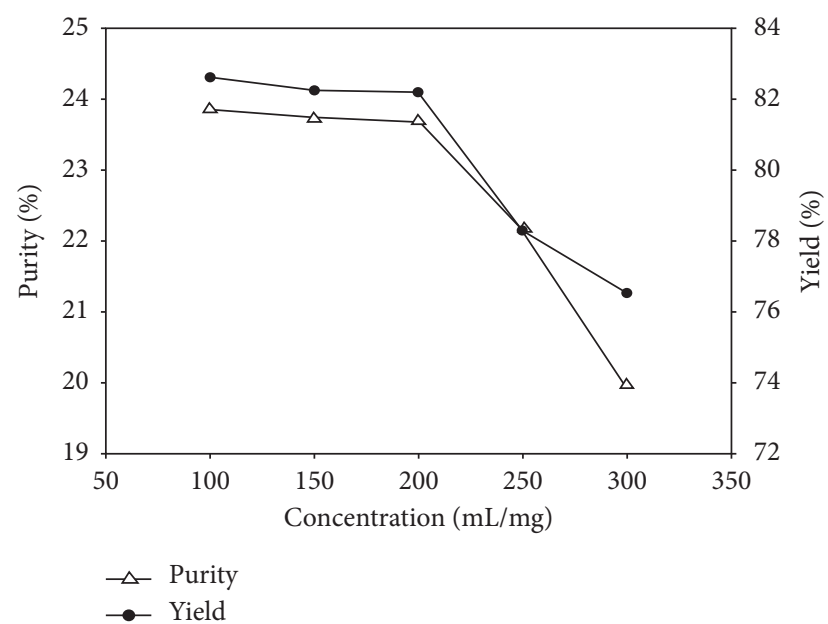

FIgURE 2: The effect of feed concentration on the purification of BKBA.

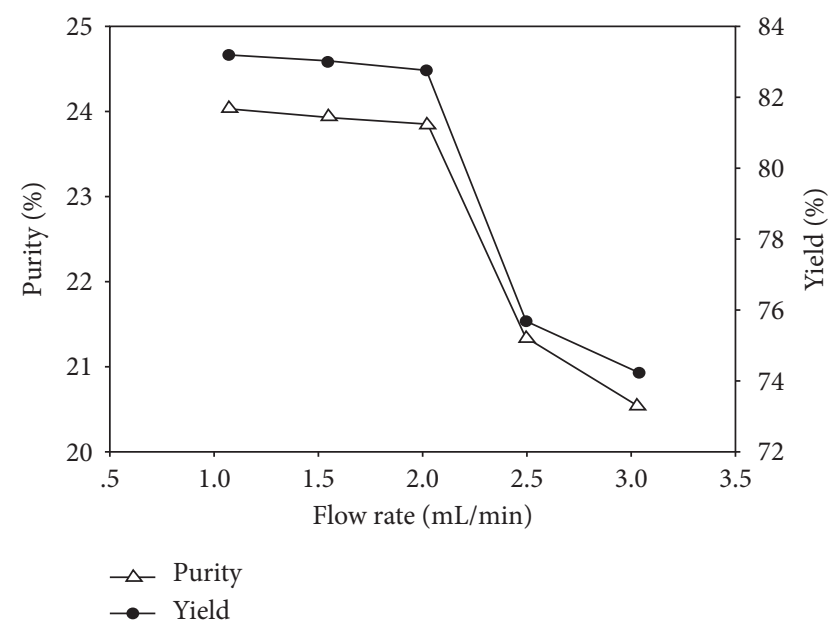

FIGURE 3: The effect of desorption flow rate on purification of BKBA.

in the following order: $40 \%$ ethanol $>20 \%$ ethanol $>\mathrm{Vc}$ (positive control) $>60 \%$ ethanol $>$ distilled water. Therefore, the best results for scavenging activity for BKBA were with $40 \%$ ethanol solution. The $40 \%$ ethanol elution solutions exhibited higher antioxidant activity than ascorbic acid. However, the $\mathrm{IC}_{50} / \mathrm{DPPH}$ of BKBA we obtained was slightly lower than the $\mathrm{IC}_{50} / \mathrm{DPPH}$ of the anthocyanins of the fruit of Berberis heteropoda Schrenk $(2.25 \mu \mathrm{g} / \mathrm{mL})$ reported by Sun et al. [45], and the $\mathrm{IC}_{50} / \mathrm{ABTS}+\bullet$ of BKBA we obtained was slightly lower than the $\mathrm{IC}_{50} / \mathrm{ABTS}+\bullet$ of the anthocyanins of blueberry $(4.33 \mu \mathrm{g} / \mathrm{mL})$ reported by Zhao et al. [46]. This was because we removed the $20 \%$ and $60 \%$ ethanol solution, and the $20 \%$ and $60 \%$ ethanol elution solutions had similar antioxidant activity to ascorbic acid, so the purity of BKBA was lower and may have contained proteins, polysaccharides, flavonoids, and other impurities.

Thus, we collected the $40 \%$ ethanol elution solution during the SMB.

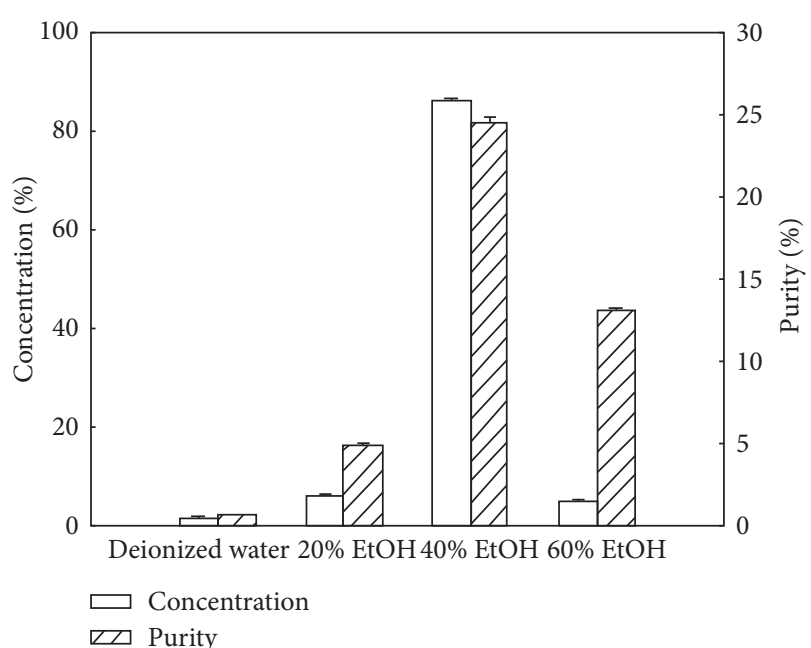

FIgURE 4: The result of purification of BKBA by preparative chromatography.

3.3. SMB Purification for BKBA. Using the column chromatography results and free scavenging capacity research and correlation theory, we assigned the zoning mode of SMB and the primary parameters of SMB. The SMB had five zones: adsorption, refining, desorbing, regenerative, and water washing zones. These five zones had six (series connection), four (series connection), three (series connection), four (parallel countercurrent), and three columns (series connection), respectively. The primary parameters of SMBIEC were adsorption zone flow rate of $12 \mathrm{~mL} / \mathrm{min}$, refined zone flow rate of $26 \mathrm{~mL} / \mathrm{min}$, desorbing zone flow rate of $24 \mathrm{~mL} / \mathrm{min}$, regenerative zone flow rate of $20 \mathrm{~mL} / \mathrm{min}$, water washing zone flow rate of $30 \mathrm{~mL} / \mathrm{min}$, and switching time of $1080 \mathrm{~s}$. The results (Table 2) were obtained through experimental optimization.

The SMB test results showed that the no. 4 test was better than the other six tests (Table 2), when we considered the quantity of treatment, ratio of material to water, purity, and yield. The best conditions were an adsorption zone flow rate of $12.5 \mathrm{~mL} / \mathrm{min}$, refined zone flow rate of $28.5 \mathrm{~mL} / \mathrm{min}$, desorbing zone flow rate of $24.5 \mathrm{~mL} / \mathrm{min}$, regenerative zone flow rate of $22.5 \mathrm{~mL} / \mathrm{min}$, water washing zone flow rate of $38.5 \mathrm{~mL} / \mathrm{min}$, and switching time of $1,080 \mathrm{~s}$, which resulted in a purity and yield of BKBA of $24.61 \pm 0.21 \%$ and $87.85 \pm 0.32 \%$, respectively.

3.4. UPLC-MS Analysis for 40\% Ethanol Elution Components. Anthocyanins have a similar structure to flavonoids and they can easily be confused in routine mass spectrometry analysis, so we used positive ion detection, meaning that the main anthocyanins were concentrated within 7-15 $\mathrm{min}$ [45]. The UPLC-MS analysis for $40 \%$ ethanol elution indicated three compounds in the $40 \%$ ethanol elution of BKBA (Figure 5).

3.5. Component 1. The peak time of compound 1 was $9.26 \mathrm{~min},[\mathrm{M}]^{+} \mathrm{m} / \mathrm{z}$ was $465.1019 \mathrm{Da}$, and the molecular formula was $\mathrm{C}_{21} \mathrm{H}_{21} \mathrm{O}_{12}{ }^{+}$. According to the secondary mass spectrometry, the parent nucleus of the compound was 
TABLE 1: The $\mathrm{IC}_{50}$ of free radical scavenging capacity for BKBA $(\mu \mathrm{g} / \mathrm{mL})$.

\begin{tabular}{lcc}
\hline Sample & IC $_{50}$ of DPPH scavenging activity & IC $_{50}$ of ABTS+・ scavenging activity \\
\hline Distilled water & $18.34 \pm 0.36^{\mathrm{e}}$ & $35.21 \pm 0.52^{\mathrm{e}}$ \\
$20 \%$ ethanol & $4.86 \pm 0.05^{\mathrm{b}}$ & $8.17 \pm 0.13^{\mathrm{b}}$ \\
$40 \%$ ethanol & $0.95 \pm 0.03^{\mathrm{a}}$ & $2.14 \pm 0.11^{\mathrm{a}}$ \\
$60 \%$ & $7.79 \pm 0.22^{\mathrm{d}}$ & $16.32 \pm 0.35^{\mathrm{d}}$ \\
$V_{\mathrm{C}}$ & $5.26 \pm 0.08^{\mathrm{c}}$ & $9.69 \pm 0.16^{\mathrm{c}}$ \\
\hline
\end{tabular}

Letters a-e indicate intergroup differences at $\rho<0.05$.

TABLE 2: SMB operating conditions and test results.

\begin{tabular}{|c|c|c|c|c|c|c|c|c|}
\hline No. & $\begin{array}{l}\text { Adsorption } \\
\text { zone flow rate } \\
(\mathrm{mL} / \mathrm{min})\end{array}$ & $\begin{array}{l}\text { Refined } \\
\text { zone flow } \\
\text { rate } \\
(\mathrm{mL} / \mathrm{min})\end{array}$ & $\begin{array}{l}\text { Desorbing } \\
\text { zone flow rate } \\
(\mathrm{mL} / \mathrm{min})\end{array}$ & $\begin{array}{l}\text { Regenerative zone } \\
\text { flow rate }(\mathrm{mL} / \mathrm{min})\end{array}$ & $\begin{array}{l}\text { Water washing } \\
\text { zone flow rate } \\
(\mathrm{mL} / \mathrm{min})\end{array}$ & $\begin{array}{l}\text { Switching } \\
\text { time }(\mathrm{s})\end{array}$ & Purity (\%) & Yield (\%) \\
\hline 1 & 11.0 & 27.5 & 23.5 & 23.5 & 32.0 & 1260 & $23.22 \pm 0.15^{\mathrm{c}}$ & $80.61 \pm 0.22^{\mathrm{d}}$ \\
\hline 2 & 11.0 & 24.5 & 23.5 & 26.5 & 32.0 & 1260 & $24.34 \pm 0.18^{\mathrm{a}}$ & $84.92 \pm 0.26^{\mathrm{c}}$ \\
\hline 3 & 12.5 & 29.5 & 24.5 & 22.0 & 37.5 & 1260 & $20.28 \pm 0.12^{f}$ & $79.84 \pm 0.19^{\mathrm{e}}$ \\
\hline 4 & 12.5 & 28.5 & 24.5 & 22.5 & 38.5 & 1080 & $24.61 \pm 0.21 a$ & $87.85 \pm 0.32^{b}$ \\
\hline 5 & 14.5 & 36.5 & 24.5 & 28.5 & 42.0 & 1080 & $22.19 \pm 0.11^{\mathrm{d}}$ & $79.62 \pm 0.28^{\mathrm{e}}$ \\
\hline 6 & 14.5 & 38.5 & 26.5 & 26.0 & 42.5 & 1080 & $21.32 \pm 0.09^{\mathrm{e}}$ & $90.91 \pm 0.36^{\mathrm{a}}$ \\
\hline 7 & 16.0 & 42.5 & 30.0 & 29.5 & 45.5 & 1080 & $23.78 \pm 0.14^{\mathrm{b}}$ & $88.36 \pm 0.35^{\mathrm{b}}$ \\
\hline
\end{tabular}

Letters a-f indicate intergroup differences $(P<0.05)$.

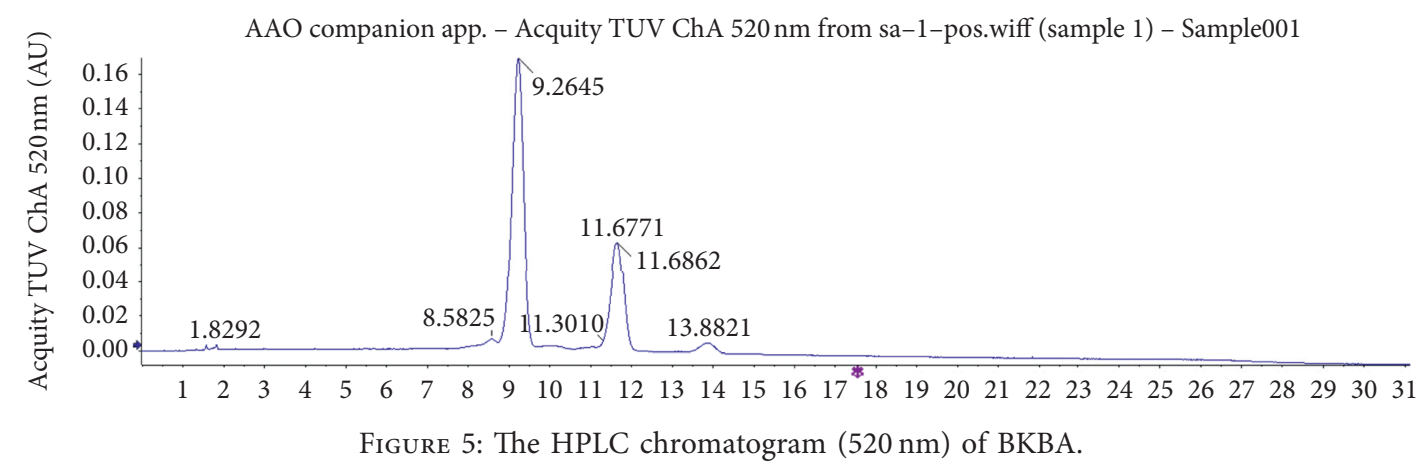

$303 \mathrm{Da}$, which indicated delphinidin. There was a six-carbon sugar structure in the compound. Searching the SciFinder and Reaxys database showed the compound to be delphinidin-3-O-glucoside. The mass and mass 2 spectra and the possible structural formula of compound 1 are shown in Figure 6.

3.6. Component 2. The peak time of compound 2 was $11.67 \mathrm{~min},[\mathrm{M}]^{+} \mathrm{m} / z$ was $479.1173 \mathrm{Da}$, and the molecular formula was $\mathrm{C}_{22} \mathrm{H}_{23} \mathrm{O}_{12}{ }^{+}$, from the results of high resolution mass spectrometry. According to the second-order mass spectrometry, the parent nucleus of the compound was $317 \mathrm{Da}$, with one more methylene than the parent nucleus of component 1 , indicating that it was petunidin. The $\mathrm{m} / z 317$ [M-162] and $m / z 302$ [M-162-15] implied that there was a six-carbon structure in the compound. The structures of carbohydrate and methoxy groups were retrieved using the SciFinder and Reaxys databases and showed compound 2 to be petunidin-3-O-glucoside. The mass and mass 2 spectra and the possible structure formula of the compound are shown in Figure 7.

3.7. Component 3. The peak time of compound 3 was $11.67 \mathrm{~min},[\mathrm{M}]^{+} \mathrm{m} / z$ was $493.1331 \mathrm{Da}$, and the fitting formula was $\mathrm{C}_{23} \mathrm{H}_{25} \mathrm{O}_{12}{ }^{+}$, using the results of high resolution mass spectrometry. According to the secondorder mass spectrometry, the parent nucleus of the compound was $331 \mathrm{Da}$, with one more methylene than the parent nucleus of component 2, making it malvidin. The $\mathrm{m} / z 331$ [M-162] indicated that it included a six-carbon sugar structure. Using the SciFinder and Reaxys databases, the structures of carbohydrate and methoxy groups were retrieved and showed compound 3 to be a malvidin3-O-glucoside. The mass and mass 2 spectra and the possible structure formula of the compound are shown in Figure 8. 


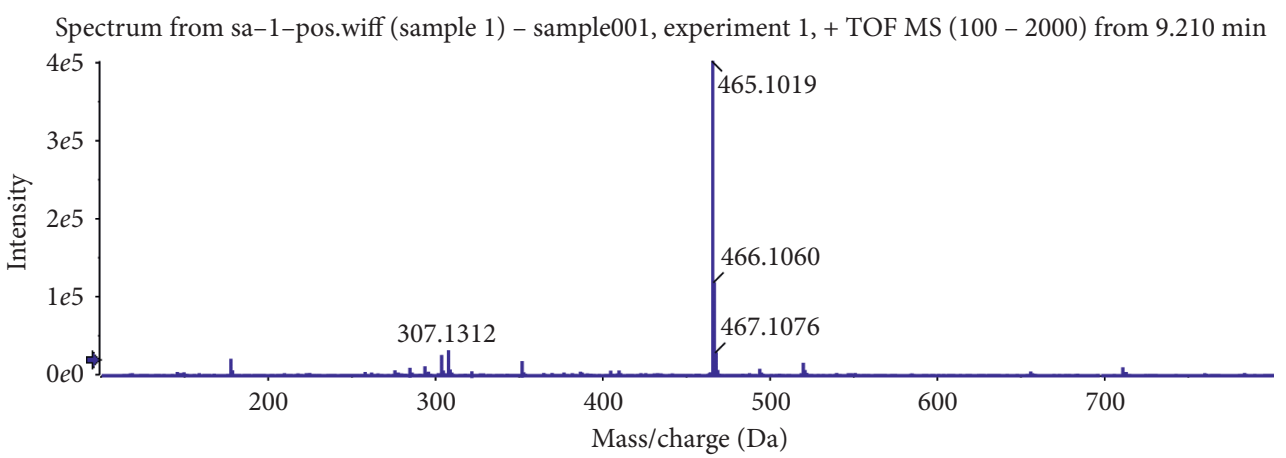

(a)

Spectrum from sa-1-pos.wiff (sample 1) - sample001, experiment 7, + TOF MS^2 (50 - 2000) from $8.941 \mathrm{~min}$

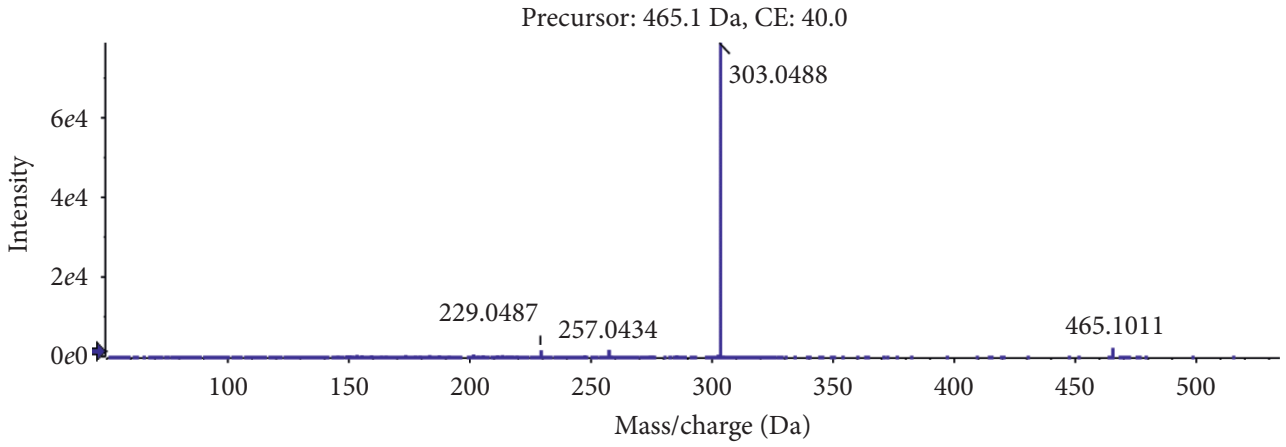

(b)

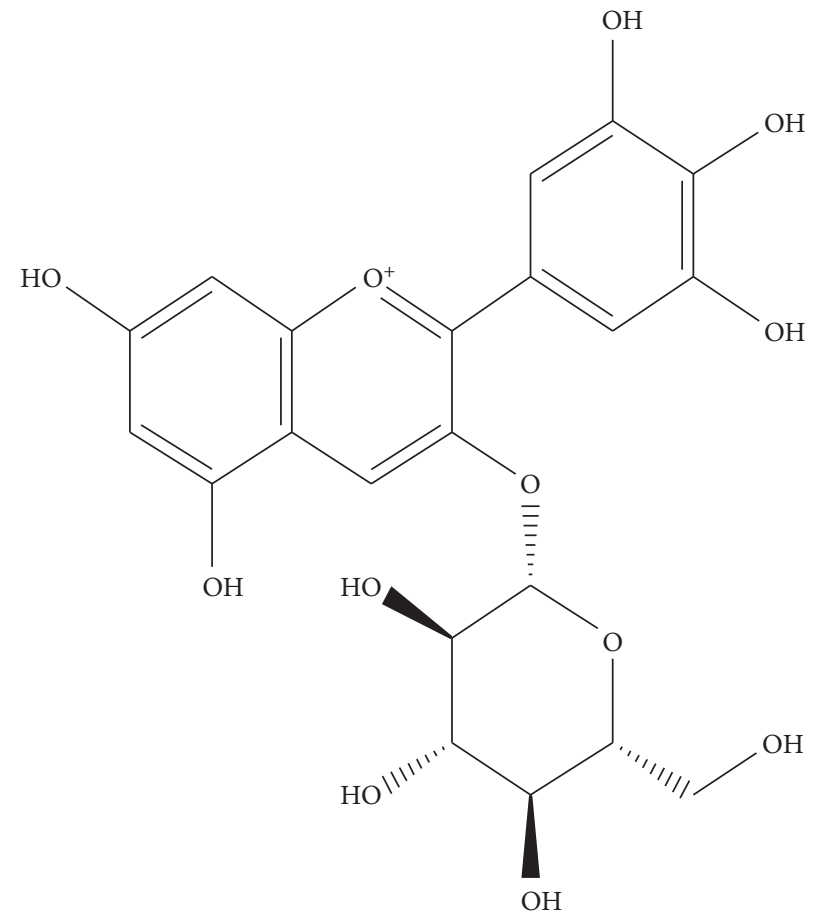

Chemical formula: $\mathrm{C}_{21} \mathrm{H}_{21} \mathrm{O}_{12}{ }^{+}$

Exact mass: 465.1028

(c)

FIGURE 6: The first class two-level mass spectrogram and the possible structure formula of component 1. 


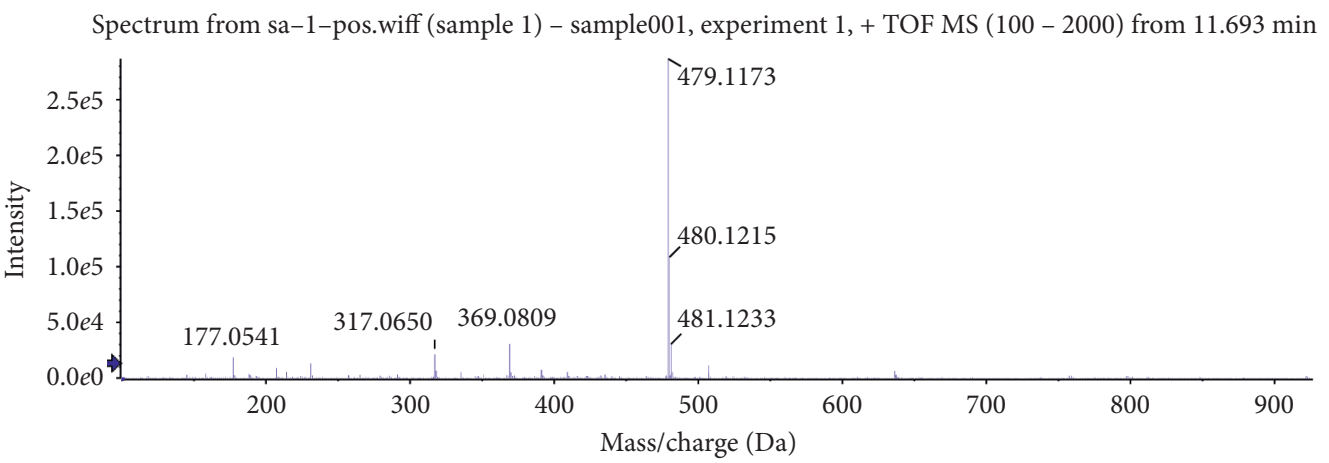

(a)

Spectrum from sa-1-pos.wiff (sample 1) - sample001, experiment 9, + TOF MS^2 (50 - 2000) from 11.539 min

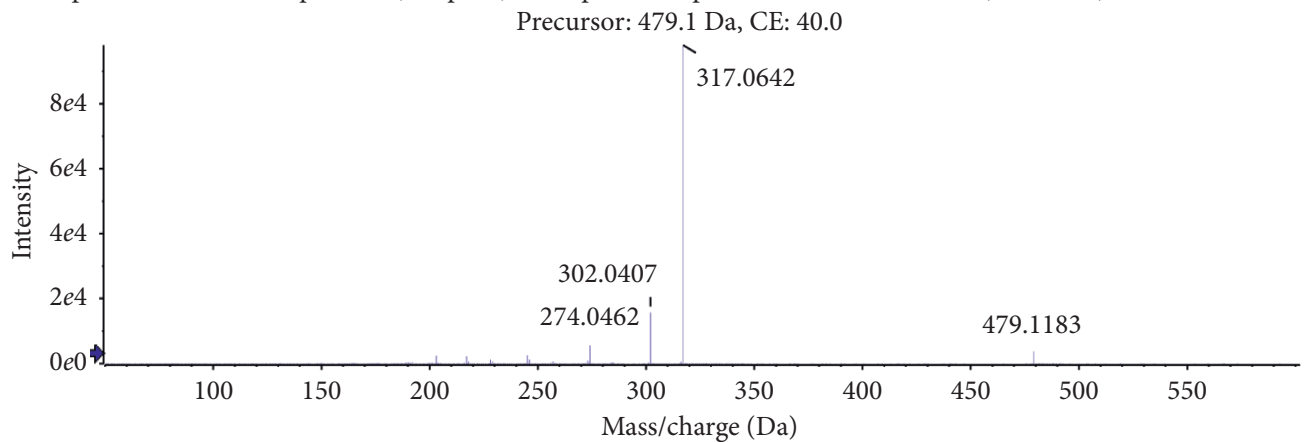

(b)

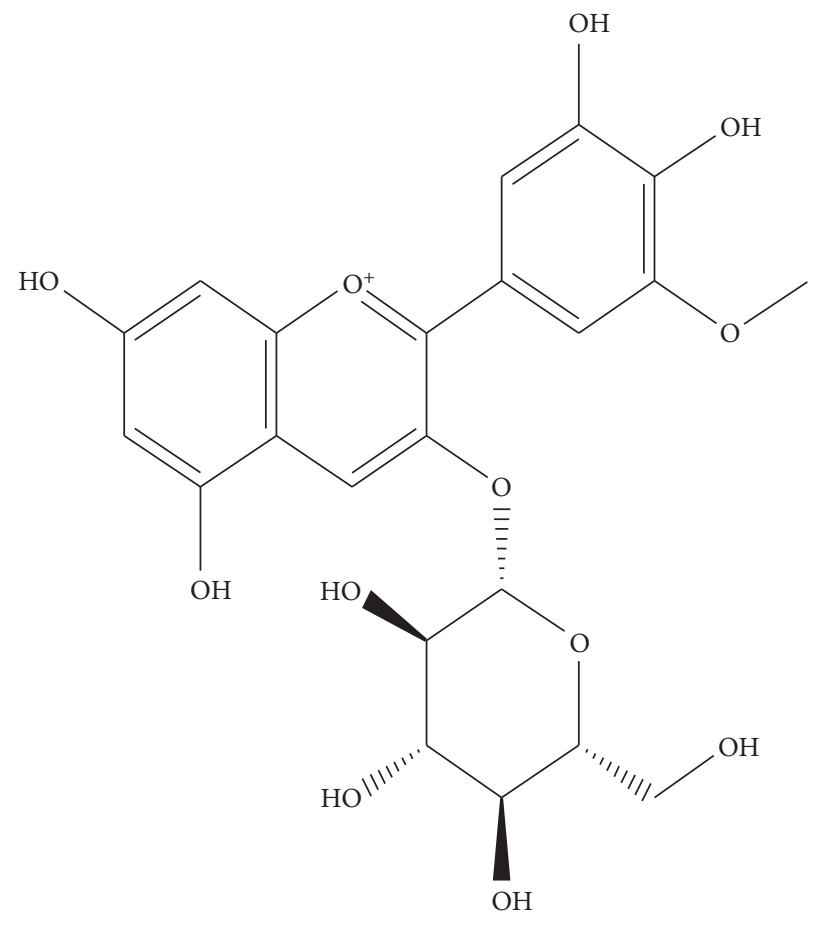

Chemical formula: $\mathrm{C}_{22} \mathrm{H}_{23} \mathrm{O}_{12}{ }^{+}$

Exact mass: 479.1184

(c)

Figure 7: The first class two-level mass spectrogram and the possible structure formula of component 2. 
Spectrum from sa-1-pos.wiff (sample 1)-sample001, experiment 1, + TOF MS (100 - 2000) from $13.792 \mathrm{~min}$

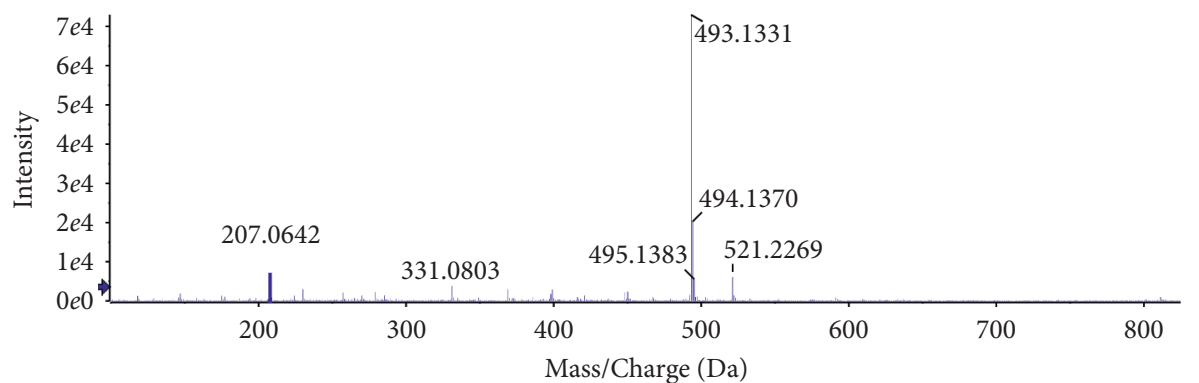

(a)

Spectrum from sa-1-pos.wiff (sample 1)-sample001, experiment 5, + TOF MS ${ }^{2}(50-2000)$ from $12.980 \mathrm{~min}$ Precursor: 493.1 Da, CE: 40.0

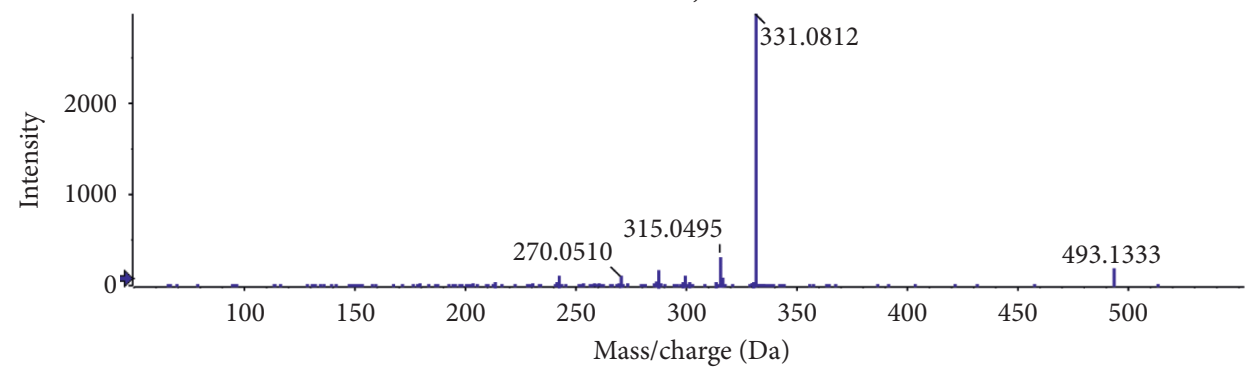

(b)

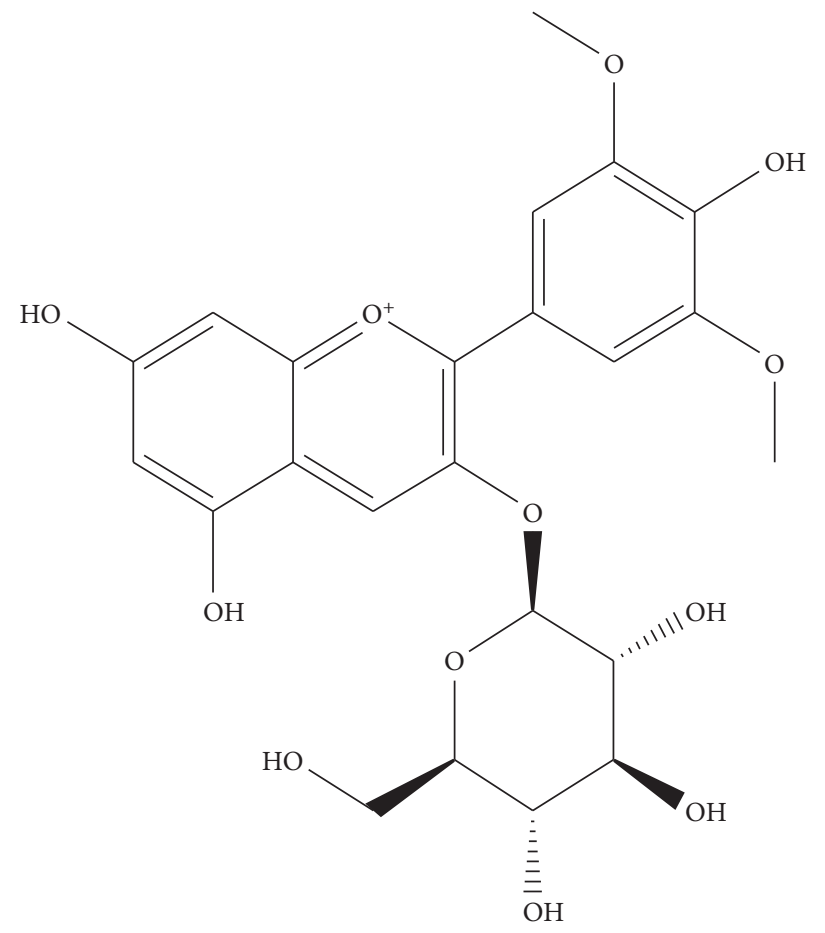

Chemical formula: $\mathrm{C}_{23} \mathrm{H}_{25} \mathrm{O}_{12}{ }^{+}$

Exact mass: 493.1341

(c)

Figure 8: The first class two-level mass spectrogram and the possible structure formula of component 3. 
TABLE 3: Comparison of TMB and SMB.

\begin{tabular}{lcc}
\hline Items & Column chromatography & SMB chromatography \\
\hline Chromatographic columns numbers & 20 & 20 \\
Resin addition & $5 \mathrm{~L}$ & $5 \mathrm{~L}$ \\
Feeding mode & Indirect & Continuity \\
Control mode & Manual & Automatic \\
Processing quantity & $3.6 \mathrm{~L} / \mathrm{d}$ & $18 \mathrm{~L} / \mathrm{d}$ \\
Alcohol consumption: processing quantity & $6.4^{\mathrm{b}}$ & $3.04^{\mathrm{a}}$ \\
Water consumption: processing quantity & $9.6^{\mathrm{b}}$ & $6.08^{\mathrm{a}}$ \\
BKBA purity (\%) & $24.35 \pm 0.16 \%^{\mathrm{a}}$ & $24.61 \pm 0.21 \%^{\mathrm{a}}$ \\
BKBA yield (\%) & $86.76 \pm 0.29 \%^{\mathrm{a}}$ & $87.85 \pm 0.32 \%^{\mathrm{a}}$ \\
\hline
\end{tabular}

Letters $\mathrm{a}$ and $\mathrm{b}$ indicate intergroup differences $\rho<0.05$.

\section{Discussion}

The procedures of SMB and TMB are quite different. The SMB feeding mode is continuous, and the TMB feeding mode is indirect. The SMB control mode is automatic, and the TMB control mode is manual (Table 3 ). Besides the differences in control devices, there are large differences in operation conditions. For the same resin, the treatment capacity of SMB is five times that of TMB. Under the same daily treatment capacity, the consumption of ethanol and water of SMB was only 0.48 and 0.63 times that of TMB, respectively. There were no significant differences in purity and yield between SMB and TMB separation methods (Table 3). The result was consistent with the principle of ion exchange separation. However, SMB had obvious advantages in industrial production compared with TMB. First, $\mathrm{SMB}$ is a continuous operation system of 20 separation columns. The resin in the SMB system had higher utilization rate and higher production efficiency. The TMB is a single column indirect operation system and its resin had a lower utilization rate and lower production efficiency. To achieve the same treatment capacity, SMB would require more than 20 separation columns in the TMB system. The volume of each TMB column was double that of SMB, and the floor area was increased accordingly. The SMB equipment is a well-knit structure, occupying less land, convenient for installation, and uses $1 / 2-1 / 3$ of the amount of resin of TMB. Second, compared with TMB, the amount of eluent, regenerator, and water used in SMB was $40-60 \%$ lower. Finally, the SMB method used automatic control to adjust the parameters at any time according to the needs of the production process to reach an optimal economic state. Comparison of parameters showed that the SMB system had a larger operational capacity, lower solvent consumption, lower cost, higher production efficiency, and continuous production advantage. The SMB method was therefore very suitable for the industrial production of BKBA.

To the best of our knowledge, this is the first report on the purification of BKBA by SMB. Moreover, the antioxidant activities were improved by SMB. This SMB method is of low cost; it is a simple process and a continuous operation, with obvious advantages compared with the combinatorial chromatography [47] and high-speed countercurrent chromatography aqueous two-phase system [48] in industrial production. These results are useful in guiding the industrial production of BKBA. They also provide evidence for the production and application of other agricultural byproducts. However, the results only represented the sample tested and might not be representative of the population of colored kidney beans. The separation and purification parameters of SMB in different cultivars should be tested in the future.

\section{Conclusion}

To the best of our knowledge, this is the first report on the purification of BKBA by SMB. Moreover, the antioxidant inhibition activities were improved by SMB. These results are useful as guidance for the industrial production of BKBA. It also provided evidence for the production and application of other agricultural byproducts. However, our results only represented the sample we tested and might not necessarily be representative of the population of black kidney bean. The separation and purification parameters of $\mathrm{SMB}$ in different cultivars should be tested in the future.

\section{Data Availability}

The data used to support the findings of this study are included within the article.

\section{Conflicts of Interest}

The authors declare that they have no conflicts of interest.

\section{Acknowledgments}

This study was supported by the "Millions" Science and Technology Major Special Project (2019ZX06B02) of Heilongjiang Province, the Engineering Research Center of Processing and Utilization of Grain By-Products, Ministry of Education, Youth Science and Technology Innovation Talents Project (UNPYSCT-2017111) from the Heilongjiang Education Department, and the Key Technology of Corn Functional Sugar Production (2019ZX06B02-1) from the Department of Science and Technology of Heilongjiang.

\section{References}

[1] M. P. Hojilla-Evangelista, G. W. Selling, M. A. Berhow, and R. L. Evangelista, "Extraction, composition and functional 
properties of pennycress (Thlaspi arvense L.) press cake protein," Journal of the American Oil Chemists' Society, vol. 92, no. 6, pp. 905-914, 2015.

[2] Q. He, X. Sun, S. He et al., "PEGylation of black kidney bean (Phaseolus vulgaris L.) protein isolate with potential functional properties," Colloids and Surfaces B: Biointerfaces, vol. 164, pp. 89-97, 2018.

[3] N. Sutivisedsak, B. R. Moser, B. K. Sharma et al., "Physical properties and fatty acid profiles of oils from black, kidney, great northern, and pinto beans," Journal of the American Oil Chemists' Society, vol. 88, no. 2, pp. 193-200, 2011.

[4] S. He, J. Shi, E. Walid, Y. Ma, and S. J. Xue, "Extraction and purification of a lectin from small black kidney bean (Phaseolus vulgaris) using a reversed micellar system," Process Biochemistry, vol. 48, no. 4, pp. 746-752, 2013.

[5] S. Kumar, A. K. Verma, A. Misra et al., "Allergenic responses of red kidney bean (Phaseolus vulgaris cv chitra) polypeptides in BALB/C mice recognized by bronchial asthma and allergic rhinitis patients," Food Research International, vol. 44, no. 9, pp. 2870-2879, 2011.

[6] M. Siddiq, R. Ravi, J. B. Harte, and K. D. Dolan, "Physical and functional characteristics of selected dry bean (Phaseolus vulgaris L.) flours," LWT-Food Science and Technology, vol. 43, no. 2, pp. 230-237, 2010.

[7] S.-k. Du, H. Jiang, Y. Ai, and J.-l. Jane, "Physicochemical properties and digestibility of common bean (Phaseolus vulgaris L.) starches," Carbohydrate Polymers, vol. 108, no. 1, pp. 200-205, 2014.

[8] S. Gupta, G. S. Chhabra, C. Liu, J. S. Bakshi, and S. K. Sathe, "Functional properties of select dry bean seeds and flours," Journal of Food Science, vol. 83, no. 8, pp. 2052-2061, 2018.

[9] M. Dueñas, C. Martínez-Villaluenga, R. I. Limón, E. Peñas, and J. Frias, "Effect of germination and elicitation on phenolic composition and bioactivity of kidney beans," Food Research International, vol. 70, pp. 55-63, 2015.

[10] P. X. Chen, H. Zhang, M. F. Marcone et al., "Anti-inflammatory effects of phenolic-rich cranberry bean (Phaseolus vulgaris L.) extracts and enhanced cellular antioxidant enzyme activities in Caco-2 cells," Journal of Functional Foods, vol. 38, pp. 675-685, 2017.

[11] B. Xu and S. K. C. Chang, "Total phenolic, phenolic acid, anthocyanin, flavan-3-ol, and flavonol profiles and antioxidant properties of pinto and black beans (Phaseolus vulgaris L.) as affected by thermal processing," Journal of Agricultural and Food Chemistry, vol. 57, no. 11, pp. 4754-4764, 2009.

[12] T. Madhujith and F. Hahidi Shahidi, "Antioxidant potential of pea beans (Phaseolus vulgaris L.)," Journal of Food Science, vol. 70, no. 1, pp. S85-S90, 2010.

[13] T. J. Ha, M.-H. Lee, C.-H. Park et al., "Identification and characterization of anthocyanins in yard-long beans (Vigna unguiculata ssp. sesquipedalis L.) by high-performance liquid chromatography with diode array detection and electrospray ionization/mass spectrometry (HPLC-DAD-ESI/MS) analysis," Journal of Agricultural and Food Chemistry, vol. 58, no. 4, pp. 2571-2576, 2010.

[14] B. D. Oomah, A. Cardador-Martínez, and G. Loarca-Piña, "Phenolics and antioxidative activities in common beans (Phaseolus vulgaris L.)," Journal of the Science of Food and Agriculture, vol. 85, no. 6, pp. 935-942, 2005.

[15] L. Mojica, M. Berhow, and E. Gonzalez de Mejia, "Black bean anthocyanin-rich extracts as food colorants: physicochemical stability and antidiabetes potential," Food Chemistry, vol. 229, pp. 628-639, 2017.
[16] A. López, T. El-Naggar, M. Dueñas et al., "Effect of cooking and germination on phenolic composition and biological properties of dark beans (Phaseolus vulgaris L.)," Food Chemistry, vol. 138, no. 1, pp. 547-555, 2013.

[17] C. Jampani, A. Naik, and K. S. M. S. Raghavarao, "Purification of anthocyanins from jamun (Syzygium cumini L.) employing adsorption," Separation and Purification Technology, vol. 125, no. 4, pp. 170-178, 2014.

[18] Y. Yang, X. Yuan, Y. Xu, and Z. Yu, "Purification of anthocyanins from extracts of red raspberry using macroporous resin," International Journal of Food Properties, vol. 18, no. 5, pp. 1046-1058, 2015.

[19] J. Heinonen, H. Farahmandazad, A. Vuorinen, H. Kallio, B. Yang, and T. Sainio, "Extraction and purification of anthocyanins from purple-fleshed potato," Food and Bioproducts Processing, vol. 99, no. 7, pp. 136-146, 2016.

[20] M. Bleve, L. Ciurlia, E. Erroi et al., "An innovative method for the purification of anthocyanins from grape skin extracts by using liquid and sub-critical carbon dioxide," Separation and Purification Technology, vol. 64, no. 2, pp. 192-197, 2008.

[21] O. Acosta, F. Vaillant, A. M. Pérez, and M. Dornier, "Potential of ultrafiltration for separation and purification of ellagitannins in blackberry (Rubus adenotrichus Schltdl.) juice," Separation and Purification Technology, vol. 125, no. 4, pp. 120-125, 2014.

[22] Y. Liu, N. Murakami, L. Wang, and S. Zhang, "Preparative high-performance liquid chromatography for the purification of natural acylated anthocyanins from red radish (Raphanus sativus L.)," Journal of Chromatographic Science, vol. 46, no. 8, pp. 743-746, 2008.

[23] X. Wu, L. Liang, Y. Zou et al., "Aqueous two-phase extraction, identification and antioxidant activity of anthocyanins from mulberry (Morus atropurpurea Roxb.)," Food Chemistry, vol. 129, no. 2, pp. 443-453, 2011.

[24] B. Qin, X. Liu, H. Cui, Y. Ma, Z. Wang, and J. Han, “Aqueous two-phase assisted by ultrasound for the extraction of anthocyanins from Lycium ruthenicum Murr," Preparative Biochemistry \& Biotechnology, vol. 47, no. 9, pp. 881-888, 2017.

[25] Á. S. Lima, C. M. F. Soares, R. Paltram, H. Halbwirth, and K. Bica, "Extraction and consecutive purification of anthocyanins from grape pomace using ionic liquid solutions," Fluid Phase Equilibria, vol. 451, no. 11, pp. 68-78, 2017.

[26] A. Degenhardt, H. Knapp, and P. Winterhalter, "Separation and purification of anthocyanins by high-speed countercurrent chromatography and screening for antioxidant activity," Journal of Agricultural and Food Chemistry, vol. 48, no. 2, pp. 338-343, 2000.

[27] R. E. Asenstorfer, A. L. Morgan, Y. Hayasaka, M. Sedgley, and G. P. Jones, "Purification of anthocyanins from species of Banksia and Acacia using high-voltage paper electrophoresis," Phytochemical Analysis, vol. 14, no. 3, pp. 150-154, 2003.

[28] S.-q. Cao, S.-y. Pan, X.-l. Yao, and H.-f. Fu, "Isolation and purification of anthocyanins from blood oranges by column chromatography," Agricultural Sciences in China, vol. 9, no. 2, pp. 207-215, 2010.

[29] L. G. D’Alessandro, P. Vauchel, R. Przybylski, G. Chataigné, L. Nikov, and K. Dimitrov, "Integrated process extraction adsorption for selective recovery of antioxidant phenolics from Aronia melanocarpa berries," Separation and Purification Technology, vol. 120, no. 12, pp. 92-101, 2013.

[30] C. Jampani and K. S. M. S. Raghavarao, "Process integration for purification and concentration of red cabbage (Brassica 
oleracea L.) anthocyanins," Separation and Purification Technology, vol. 141, no. 2, pp. 10-16, 2015.

[31] E. Wang, Y. Yin, C. Xu, and J. Liu, "Isolation of high-purity anthocyanin mixtures and monomers from blueberries using combined chromatographic techniques," Journal of Chromatography A, vol. 1327, no. 1, pp. 39-48, 2014.

[32] V. Girard, N.-J. Hilbold, C. K. S. Ng et al., "Large-scale monoclonal antibody purification by continuous chromatography, from process design to scale-up," Journal of Biotechnology, vol. 213, pp. 65-73, 2015.

[33] G. Iberer, H. Schwinn, D. Josić, A. Jungbauer, and A. Buchacher, "Improved performance of protein separation by continuous annular chromatography in the size-exclusion mode," Journal of Chromatography A, vol. 921, no. 1, pp. 15-24, 2001.

[34] J. Zhu, W. Cui, W. Xiao et al., "Isolation and enrichment of Ginkgo biloba extract by a continuous chromatography system," Journal of Separation Science, vol. 41, no. 11, pp. 2432-2440, 2018.

[35] L. P. Zhang, Study on a Novel Extraction and Purification Technology of Heparin and Bioactivity of Degraded Heparin, Jilin University, Changchun, China, 2010.

[36] L. Y. Li, D. W. Song, J. J. Diao, P. Y. Jia, and L. P. Zhang, "Adsorption characteristics of AB-8 resin for anthocyanins from Lonicera edulis Turcz," Natural Product Research and Development, vol. 28, no. 8, pp. 1289-1295, 2016.

[37] H. Z. Wang, Y. Zhu, Y. Zhu et al., "Phenolic composition and antioxidant activity of seed coats of kidney beans with different colors," Food Science, vol. 41, no. 12, pp. 204-210, 2020.

[38] W. J. Zhao and Y. W. Zhao, "Optimization test on extraction process of anthocyanin pigment from black kidney bean," Modern Agricultural Science and Technology, vol. 278, no. 16, pp. 244-247, 2016.

[39] L. Li, W. Liu, D. Song, C. Li, P. Jia, and G. Niu, "Simulated moving bed purification for flavonoids from tartary buckwheat shell," Journal of Chromatographic Science, vol. 58, no. 4, pp. 362-372, 2020.

[40] Y. Wang, G. Luan, W. Zhou et al., "Subcritical water extraction, UPLC-triple-TOF/MS analysis and antioxidant activity of anthocyanins from Lycium ruthenicum Murr," Food Chemistry, vol. 249, no. 5, pp. 119-126, 2018.

[41] C. P. Nie, J. Yang, D. Wu, L. P. Wan, and G. P. Liang, "Inhibitory activities on $\alpha$-glucosidase and composition analysis of different fractions of ethanol extraction from Actinidia chinensis radix," Chemical Research in Chinese Universities, vol. 35, no. 10, pp. 823-829, 2019.

[42] G. Maeda, K. Takara, K. Wada et al., "Evaluation of antioxidant activity of vegetables from Okinawa prefecture and determination of some antioxidative compounds," Food Science and Technology Research, vol. 12, no. 1, pp. 8-14, 2006.

[43] M. B. Arnao, A. Cano, and M. Acosta, "The hydrophilic and lipophilic contribution to total antioxidant activity," Food Chemistry, vol. 73, no. 2, pp. 239-244, 2001.

[44] H. Zhang, Y.-f. Yang, and Z.-q. Zhou, "Phenolic and flavonoid contents of mandarin (Citrus reticulata Blanco) fruit tissues and their antioxidant capacity as evaluated by DPPH and ABTS methods," Journal of Integrative Agriculture, vol. 17, no. 1, pp. 256-263, 2018.

[45] L.-L. Sun, W. Gao, M.-M. Zhang et al., "Composition and antioxidant activity of the anthocyanins of the fruit of Berberis heteropoda Schrenk," Molecules, vol. 19, no. 11, pp. 19078-19096, 2014.

[46] H. F. Zhao, W. L. Wu, L. Ma, J. H. Teng, B. Yao, and W. L. Li, "Separation of polyphenols from blueberry based on antioxidative activities," Science and Technology of Food Industry, vol. 36, no. 5, pp. 251-254, 2015.

[47] N. Chorfa, S. Savard, and K. Belkacemi, "An efficient method for high-purity anthocyanin isomers isolation from wild blueberries and their radical scavenging activity," Food Chemistry, vol. 197, pp. 1226-1234, 2016.

[48] Y. Wu, Y. Wang, W. Zhang et al., "Extraction and preliminary purification of anthocyanins from grape juice in aqueous twophase system," Separation and Purification Technology, vol. 124, no. 6, pp. 170-178, 2014. 